\title{
How Covid-19 Pandemic Reshaped Cultural Environment in Italy and Ukraine: Facebook Content Analysis
}

\author{
Nataliia Kochkina ${ }^{1}$, Marina Riccardi ${ }^{2}$ \\ ${ }^{1}$ ORCID iD: 0000-0003-2464-4081, Taras Shevchenko National University of Kyiv, \\ Vasylkivska Street 90a, Kyiv 03022, Ukraine \\ ${ }^{2}$ ORCID iD: 0000-0003-4409-9930, Libera Università Internazionale Degli Studi \\ Sociali Guido Carli, 32 Viale Romania, Rome 00197, Italy \\ *Corresponding author, e-mail: nataliakochkina@knu.ua
}

\begin{abstract}
The need to incorporate cultural aspects into business practice is long-standing. The cultural environment in Ukraine and Italy was reshaped, especially during the Covid-19 pandemic. Social networks reflected such transformation both at the personal level and in the business activities of national companies on Facebook, Twitter, Instagram, and other media. Facebook pages were analyzed as the most popular social platform in Ukraine and Italy to reveal these changes. Content analysis of countries' leaders in retail, e-commerce, and service was carried out, namely EVA, Rozetka, and Nova Noshta for Ukraine; and Conad, Bottega Verde, and Italo Treno for Italy. Two-phase desk research was conducted with ten research questions for each cultural dimension encoded in a binary system. The research has shown that Ukrainian business still manifests collaborative problem solving, compliance with social standards, and the value of human life. It demonstrates a low level of power distance and uncertainty avoidance. Ukraine is gradually changing its paradigm of thinking to a more hedonic and individualistic similar to Western Europe. In contrast, Italy shows less respect for power in all its manifestations and a greater willingness to take risks than before. The country has become less goal-oriented, restrained, and masculine but more collectivistic.
\end{abstract}

Keywords: Hofstede's Cultural Dimensions, Covid-19, Doing Business in Ukraine and Italy, Facebook, Content Analysis.

\section{Introduction}

In the late 1970s, the need to consider cultural peculiarities in business practice became evident. As a result, scientists began to look at company management through a cross-cultural lens. Since then, the Hofstede model (G. Hofstede, 1980) has been used to describe cultural differences. Six main dimensions were contemplated as criteria to represent national cultures, namely: Individualism vs Collectivism, High vs Low Power Distance, High vs Low Uncertainty Avoidance, Masculinity vs Femininity, Long-Term vs Short-Term Orientation, and Indulgence vs Restraint (G. Hofstede, 1991; G. Hofstede, 2001; G. Hofstede \& Bond, 1988; Geert Hofstede et al., 2010; Minkov, 2007).

Hofstede claimed that culture is critical for setting organizational goals and decision-making processes, impacting organizations on every level (G. Hofstede, 2001). Moreover, organizations implant cultural practices and dimensions in different ways (Taras et al., 2016). A worthwhile exchange exists between the fields of information technology and organizational studies (Orlikowski \& Barley, 2001). As a result, numerous studies of cultural influence in different spheres of business were carried out: in tourism (Huanga \& Crotts, 2019; Mazanec et al., 2015), banking, and finance (Laitinen $\&$ Suvas, 2016; Picoto \& Pinto, 2021) and so on.

Obsolescence and data unreliability of Hofstede's work was severely criticized.

Article History: Received October 31, 2020; Revised June 01, 2021; Accepted November 19, 2021; Published December 30, 2021 
Clark (2003) noticed that Hofstede's dichotomized way of portraying cultural differences might bring about generalizations and ignore the finesses and ambiguity intrinsic to national cultures. Other criticisms indicated the urgency for elaborating innovative measures of distance (Beugelsdijk et al., 2017) and the need for separating culture and country effects while carrying out tests (Kirkman et al., 2006). Minkov \& Kaasa (2021) have introduced a revised Minkov-Hofstede model based on two dimensions: individualism vs. collectivism and monumentalism vs flexibility.

The cultural environment has really changed over the years. Recent studies detect significant changes in national culture (Taras et al., 2012), particularly in Eastern European countries (Hajro et al., 2019). (Wackowski \& Blyznyuk, 2017) argue that the younger generation of Ukrainians (20-30 year olds) shows a lower level of uncertainty avoidance than indicated in Hofstede. Another research on cultural differences between Ukraine and Lithuania (Čiburienè et al., 2007) was held concerning students' study patterns (daytime, correspondence, and part-time studies). It shows that a stronger tendency to individualism among young people exists in Lithuania, much higher than in Ukraine. At the same time, the masculinity level in Lithuania is lower, and Ukrainian students are more determined when success and assertion become the basis for their motivation.

Some studies indicate at least two regionally localized kinds of mindset in Ukraine: the Eastern and the Western Ukrainian mentality (Blyznyuk \& Lepeyko, 2016; Shestakovsky, 2014). The mentality in Western Ukrainian regions is distinctly individualistic, more short-term oriented, and proved to be closer to the Polish cultural values. The mentality in Eastern, Southern, and some Central Ukrainian regions is deliberately collectivistic and, to some extent, merges the post-Soviet cultural values. However, this cultural gap almost disappeared after the 2014 Revolution of Dignity (Kochkina, 2019).

As the world gets closer and increasingly globalized, identifying the role of culture in social media exchanges and interaction becomes fundamental to assess if Hofstede's cultural framework is still up to date and if cultural indexes are transposed concretely in this new kind of communication. Social media platforms have altered market dynamics, toppling the competitive positions of organizations (Porter, 2001) and boosting the power retained by customers and stakeholders (Urban, 2005). Some studies (De Long \& Fahey, 2000) have already demonstrated that culture is the core of interaction. (Cheng et al., 2011) argued that culture and communication are different concepts, but they are inextricably linked. People with similar beliefs and mental outlooks tend to accept each other's ideas expressed on social media. A study by Fu \& Govindaraju (2010) shows that Hofstede's cultural index can be used to discover the degree of audience predilection for foreign entertainment media in addition to other possible applications in the fields of media flow, international trade, and marketing. Culturally similar countries will opt for similar media.

In recent years, numerous academicians have applied cultural dimensions analysis to communication studies in the Internet era (Lee-Won et al., 2014; Marcus \& Gould, 2000; Rosen et al., 2010). However, few inquiries contain a precise and explicit reference to each cultural dimension and social media. Some studies try to determine whether Hofstede's dimensions affect a person's desire or unwillingness to share information through the Internet. Krishen et al.(2021) study the digital self and virtual satisfaction of Americans and Spaniards. Ford \& Chan (2003) show that knowledge sharing is not 
readily accepted and acknowledged in individualistic and masculine cultures. Richardson \& Smith (2007) argue that communication can be shaped by distinct formality, courtesy, and ease or intimacy. So, let us consider that knowledge sharing takes different forms in different cultures. It is simple to deduce that the local culture's principles, customs, and beliefs can collide with the interaction tool chosen for the communication process (Gravili, 2016).

$\mathrm{Na}$ et al. (2015) studies how culture affects social media like Facebook. Following this research, Lo et al. (2017) explore if traditional Hofstede's dimensions are reflected in corporate Facebook pages. The authors scrutinized the corporations from Fortune's 'Global 500' list along the six cultural dimensions. They then related their performance on social media to Hofstede's scores of the companies' home countries. Another study by Dadgar et al. (2017) aims at discovering how cultural affiliation affects the popularity of social networks that people use at home and work. The analysis confirms that a higher level of power distance stimulates more intensive use of Facebook, Twitter, and Skype both at home and at works. Higher uncertainty avoidance factors make Skype more popular in the workplace. However, in such a case, Skype and LinkedIn are less commonly used at home. A higher level of collectivism leads to a decrease in Skype use during work.

The study by Garcia-Gavilanes et al. (2013) deals with cultural dimensions on Twitter. The study looked for a correlation between Hofstede's Individualism and Power Distance, Levine's Pace of Life (Levine, 2006), and human behavior on Twitter, namely the frequency of tweets and the intensity of communications with other social network members depending on their popularity. It was concluded that cultural differences affect both the real and the virtual world. Another recent research by Prakash \& Majumdar (2021). Analyzed the role of national culture on content creation and user engagement on Twitter in India.

Considering all the previous academic research done, by this article we try to discover how well Hofstede's cultural dimensions apply to a virtual corporate culture on Facebook for Italian and Ukrainian firms. We will demonstrate whether cross-cultural differences between Italy and Ukraine are mirrored in the way companies in two different cultures use social media to relate to their stakeholders, specifically on their Facebook pages.

We have chosen Facebook because it is the most widely used social media platform. Since its availability for corporations from 2007, companies have increasingly used it as a more conducive alternative to their websites to immediately share content and connect with their stakeholders. Our study determines whether traditional cultural dimensions are still appropriate for social media communications and are bolstered online. It may happen that the Internet, as argued by some scholars, has created its new virtual culture that guides interactions bypassing geographic and political boundaries and cultural traditions (Johnston \& Johal, 1999; Shuter, 2011; Wilson, 2010). The research aims to understand how Hofstede's cultural dimensions are reflected in the Facebook pages, mainly how companies present themselves through textual, visual, and audio content, likes, and comments. Another question is whether relevant differences in companies' social media activities from different industries and countries exist.

A company's communication activity in the context of power distance reflects its willingness to adapt to changes in the market environment and target consumers' needs by studying them. A company may be open or closed to customers, adequately respond 
even to critical comments, or delete them. A company can be based on a corporate religion or promote delegation principles, as well as in the media content.

Uncertainty avoidance is manifested in a company's desire to avoid possible risks and responsibilities in every way. It can distance itself from the content posted on the Facebook page, introduce strict rules for commenting, and punish their violation. On the other hand, a company may not be afraid to take risks and post provocative content without fear of an adverse reaction from subscribers.

Individualism level is manifested in a company communication activity. It may post content and passively wait for subscribers' reactions or actively stimulate them. A company may focus on the social responsibility of its business or demonstrate the priority of its economic interests. Savior and hero archetypes may dominate in advertising. Alternatively, it may be based on a miracle archetype that happens regardless of a person.

In the masculinity/femininity continuum, a company's media activity with a high masculinity level is characterized by its willingness to offer innovative products to the market, even without their demand (a typical example from Elon Musk's businesses). Such companies are seeking to create a blue ocean, free from competition. In contrast, company femininity may exhibit itself in a desire to soften conflict situations. Sales promotion may be based on intangible benefits and irrational USPs.

Short/long-term orientation demonstrates the power of the past while planning the future. A company with a short-term orientation focuses on traditions and demonstrates its unwillingness to change. It concentrates on momentary benefits here and now. In contrast, a long-term orientation involves investment in the future by participating in nonprofit projects. A company is ready to accept the most incredible clients' proposals about changes in its strategy.

The indulgence-restraint dimension characterizes a company's attitude towards the satisfaction of hedonistic human needs. In the case of a high level of indulgence, a company supports an informal communication style, posts entertaining content, and encourages memes creation. Commercials show a consumer seeking to get the best out of life. The archetypes of paradise, sun, water, sky, and child are widely used.

According to Hofstede Insights (2020), Italy shows a propensity for equality and power and decision-making decentralizing. Being also individualistic, the country confirms the reluctance to be controlled and bossed. On the contrary, Ukraine attaches greater importance to status symbols and centralization with top-down business relationships. It is a collectivist country where people help each other to face challenges. Long-term relationships between members of society are a prerequisite for the desired social status. Italy is a masculine success and competition-driven country. Ukraine, instead, is feminine that is more oriented toward modesty. That means that senior management can show an assertive approach, but not simple employees. Both Italians and Ukrainians, scoring high on uncertainty avoidance, do not feel comfortable with ambiguity. High degrees of formality and thorough planning in the business environment are observed. With a 61 in long terminism score, Italians tend to act business-like and ready to give in to their traditions for achieving the goal. Ukraine, with a score of 55, does not take a clear stand on this dimension. With a low (18) score in Indulgence, Ukrainians tend to be pessimistic and skeptical. Restrained societies display a reduced tolerance for any public manifestations of happiness and enjoyment of life. Italian culture scores 30 in Indulgence and has a restraint nature.

Jurnal The Messenger, Vol. 13, No. 3 (2021), pp. 194-210 


\section{Methods}

Content analysis of companies' Facebook pages was conducted based on the idea of Lo et al. (2017) of using a "yes-no" binary approach. We estimated whether textual and non-textual content on companies' Facebook pages gravitated more towards one extreme of Hofstede's rating scale over the other (e.g., indulgent or restrained). Ten research questions were formulated for each dimension in statements that one can agree or disagree with. Five of them were considered textual, and the other five multimedia content. Answers to each question were encoded in a binary 0/1 system. A score of 0 corresponded to a low level of power distance and uncertainty avoidance, collectivism, restraint, femininity, and short-term orientation. A score of 1 matched high power distance, uncertainty avoidance, individualism, indulgence, masculinity, and long-term orientation.

Power distance research questions: Research Question 1 (RQ 1): The company initiates customer surveys to identify their needs, motivations, and behavior ( 0 for "yes", 1 for "no"); RQ2: The company informs consumers about changes in strategy, product, price, and other business issues in an advisory form, suggesting feedback: "What do you think of ..." (0 for "yes", 1 for "no"); RQ3: Its senior management reports all significant news from the company ( 0 for "no", 1 for "yes"); RQ4: The company ignores or removes negative comments from subscribers ( 0 for "no", 1 for "yes"); RQ5: The company provides contacts for further interaction outside Facebook (0 for "yes", 1 for "no"); RQ6: The profile photos show the leader (owner, CEO) of the company ( 0 for "no", 1 for "yes"); RQ7: Most of the video content is performed directly by the company leader (0 for "no", 1 for "yes"); RQ8: The company usually posts photos/videos of senior management during meetings with employees, communication with customers, and other group meetings ( 0 for "yes", 1 for "no"); RQ9: The company often posts photos/videos filmed in informal situations ( 0 for "yes", 1 for "no"); and RQ10: The company allows free sharing of media content from its Facebook page (0 for "yes", 1 for "no").

Uncertainty avoidance research questions: RQ1: The company often comes out with innovative/bold proposals for the market ( 0 for "yes", 1 for "no"); RQ2: The company page contains strict commenting rules, violators are immediately banned ( 0 for "no", 1 for "yes"); RQ3: The company page has a disclaimer that it may not share the views of the page contributors ( 0 for "no", 1 for "yes"); RQ4: The company initiates customer surveys to identify their needs, motivations, and behavior (0 for "no", 1 for "yes"); RQ5: The company informs consumers about changes in strategy, product, price, and other business issues in an advisory form, suggesting feedback: "What do you think of ..." (0 for "no", 1 for "yes"); RQ6: The company allows free sharing of media content from its Facebook page (0 for "yes", 1 for "no"); RQ7: The company often posts provocative visual content and is not afraid of an adverse reaction ( 0 for "yes", 1 for "no"); RQ8: The company encourages subscribers to share its media content with their comments ( 0 for "yes", 1 for "no"); RQ9: The company avoids posting third-party content on its page and posts only links to it ( 0 for "no", 1 for "yes"); and RQ10: The company encourages subscribers to create and distribute video reviews on its product ( 0 for "yes", 1 for "no").

Individualism research questions: RQ1: The company page is active with frequent updates and active responses to comments ( 0 for "no", 1 for "yes"); RQ2: The word "we" is often used in the text ( 0 for "yes", 1 for "no"); RQ3: The company focuses on the social responsibility of its business ( 0 for "yes", 1 for "no"); RQ4: The company has thematic groups for different social groups of consumers (0 for "yes", 1 for "no"); RQ5: The company takes responsibility for inevitable blunders in its business $(0$ for "no", 1 for 
"yes"); RQ6: Multimedia content shows employees working together to solve specific business problems ( 0 for "yes", 1 for "no"); RQ7: Company commercials are built on the archetypes of hero, savior, strong man/woman (0 for "no", 1 for "yes"); RQ8: Company commercials demonstrate the collective consumption of its product ( 0 for "yes", 1 for "no"); RQ9: The company encourages subscribers to create and distribute video reviews on its product ( 0 for "yes", 1 for "no"); and RQ10: Photo/video content shows multigender groups of consumers and company employees ( 0 for "yes", 1 for "no").

Masculinity-femininity research questions: RQ1: Responses to critical comments are always polite, even for unjustified personal insults ( 0 for "yes", 1 for "no"); RQ2: Sales promotion actions involve some material gain (0 for "no", 1 for "yes"); RQ3: The company's Facebook page contains direct comparisons with competitors ( 0 for "no", 1 for "yes"); RQ4: The company initiates customer surveys to identify their needs, motivations, and behavior ( 0 for "yes", 1 for "no"); RQ5: The company often comes up with innovative offers and then creates a demand for them (0 for "no", 1 for "yes"); RQ6: Company commercials are more likely to show the product itself rather than its consumption ( 0 for "no", 1 for "yes"); RQ7: Company commercials are built on the archetypes of hero, savior, strong man/woman (0 for "no", 1 for "yes"); RQ8: The company often posts provocative content, including comparative advertising (0 for "no", 1 for "yes"); RQ9: Media content is focused on demonstrating family values and pervasive gender stereotypes ( 0 for "yes", 1 for "no"); and RQ10: Photo/video content shows mostly multi-gender or female groups of consumers and company employees ( 0 for "yes", 1 for "no").

Long-term vs short-term orientation research questions: RQ1: The company develops a customer relationship system (0 for "no", 1 for "yes"); RQ2: The Facebook page contains information about company history and its brand legend ( 0 for "no", 1 for "yes"); RQ3: The company often comes up with innovative offers and then creates a demand for them ( 0 for "no", 1 for "yes"); RQ4: The company is engaged in charity work, scientific research, and other non-profit activities ( 0 for "no", 1 for "yes"); RQ5: The company encourages subscribers to submit product, service, logistics, and other promotional propositions, including the most incredible ( 0 for "no", 1 for "yes"); RQ6: Advertising shows ready-made patterns of consumer behavior ( 0 for "yes", 1 for "no"); RQ7: Media content is focused on demonstrating family values and pervasive gender stereotypes (0 for "yes", 1 for "no"); RQ8: Advertising appeals to preserve traditions at any cost (0 for "yes", 1 for "no"); RQ9: The company posts third-party materials about the latest revolutionary discoveries that can change the market ( 0 for "no", 1 for "yes"); and RQ10: Promotion strategy is aimed at building loyalty and focusing on the long-term benefits of product consumption ( 0 for "no", 1 for "yes").

Indulgence-Restraint research questions: RQ1: The company posts entertaining content ( 0 for "no", 1 for "yes"); RQ2: The company organizes contests with instant prizes (0 for "no", 1 for "yes"); RQ3: The company page contains strict commenting rules, violators are immediately banned ( 0 for "yes", 1 for "no"); RQ4: Facebook page is maintained by formal official language (0 for "yes", 1 for "no"); RQ5: Webpage subscribers are encouraged to create and distribute memes related to the product or the company itself ( 0 for "no", 1 for "yes"); RQ6: Media content demonstrates the pleasure of using/consuming company products ( 0 for "no", 1 for "yes"); RQ7: The page is designed in a strict corporate style (0 for "yes", 1 for "no"); RQ8: Photo/video show company employees and management mainly wearing formal business clothes $(0$ for "yes", 1 for "no"); RQ9. The company often posts photos/videos filmed in informal 
situations (0 for "no", 1 for "yes"); and RQ10: The Facebook page is in bright colors (0 for "no", 1 for "yes").

\section{Results}

We conducted two-phase research in August 2018 and April 2020 to consider the possible changes in companies' media activities in the Covid-19 crisis. Socialbakers' online platform was used to discover the Top-5 Facebook industries for Italy and Ukraine. Both in 2018 and 2020, the primary industry in Ukraine by a number of local fans on Facebook is retail, followed by e-commerce, services, fashion, and food (Socialbakers, $2018 \mathrm{~b}, 2020 \mathrm{~b})$. The following ranking for Italy includes fashion, food, e-commerce, retail, and service industries (Socialbakers, 2018a, 2020a). We have chosen retail, ecommerce, and service industries to be the most massive audience for our research. Market leaders for both countries were selected: Eva (retail), Rozetka (e-commerce), Nova Poshta (services) for Ukraine, and Conad (retail), Bottega Verde (e-commerce), Italo Treno (services) for Italy.

Communication activity analysis of Ukrainian retail, e-commerce, and service companies shows a significant discrepancy between the current cultural situation and Hofstede's estimates regarding power distance. Companies are open to communication, provide contact information, and adequately respond even to negative comments from subscribers. Although the profile photo contains the company logo, it is usually aimed at sales promotion (see Figure 1). In critical situations, news can be reported by a company owner or senior management. However, in Ukrainian realities, this is more likely to indicate the proximity of management to ordinary people. Companies tend to show their employees working together, supplying products, or servicing customers. The average score for the Power Distance index was 37.

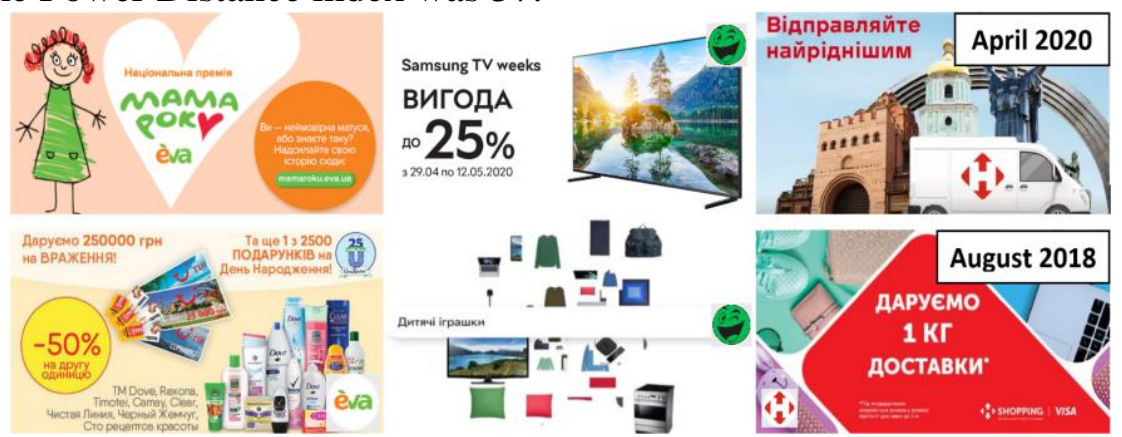

Figure 1. EVA, Rozetka \& Nova Noshta profile pictures (source: facebook.com/EVA.dp.ua/; facebook.com/rozetka.ua/;

facebook.com/nova.poshta.official/)

The Italian social media segment also shows the differences between Hofstede's ratings and the current state of the cultural environment. This is especially visible in the Covid-19 quarantine that the country started on March 12, 2020, after 'io resto a casa' (I stay home) Governmental decree. At the end of April 2020, Italy ranked third in the number of new infected globally.

The companies' communication activity in social networks demonstrates an average level of power distance (40). Companies do not initiate consumer surveys and report changes in strategy, product, and services declaratively. Contact information is provided in a limited form, often as links to other social networks. In contrast, Ukrainian companies always provide full contact details with phone numbers and addresses. Another difference 
from Ukraine is a larger formalization of visual content, usually designed in a corporate style. The main page does not contain photos of company leaders, and it does not change for years in the case of Italo Treno (see Figure 2).

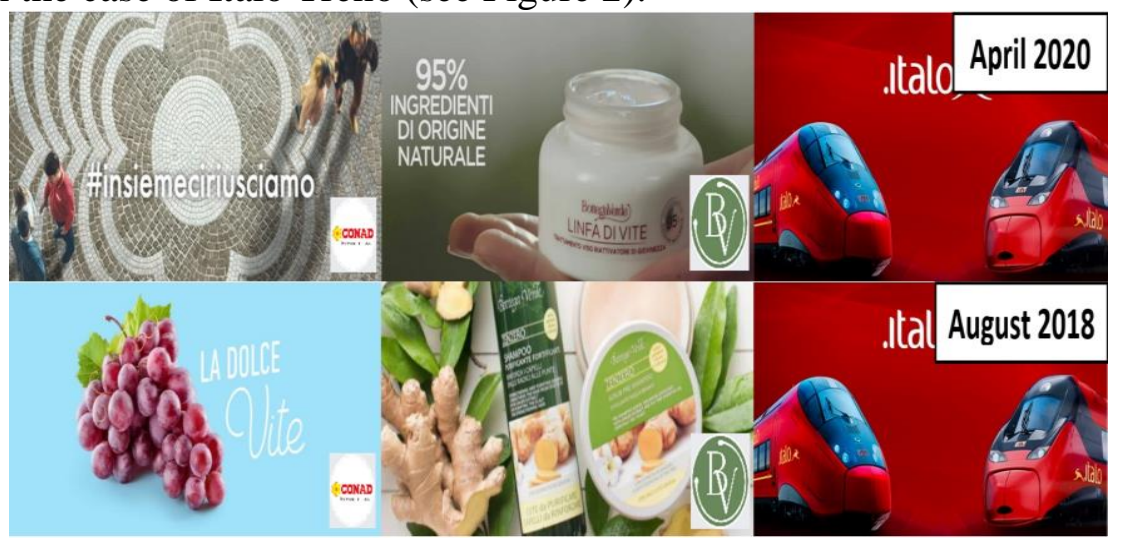

Figure 2. Conad, Bottega Verde \& Italo Treno profile pictures (source:

facebook.com/Conad/; facebook.com/BottegaVerde/; facebook.com/ItaloTreno/2

A significant discrepancy between Hofstede's estimates of the Ukrainian culture and the reality is observed in uncertainty avoidance. With an average score of 37 , Ukrainian companies are not afraid to take risks, often coming out with innovative offers. It should be noted that such behavior is typical for modern Ukrainian businesses in general. Such significant changes in the Ukrainian mentality become especially noticeable in the critical situation of Covid-19 quarantine (Ukraine went to the first lockdown on March 12, 2020).

On the other hand, Italian companies avoid aggressive market behavior and direct comparison with competitors, indicating their desire to minimize risks. Italy shows twice as much caution in the context of uncertainty as Ukraine (57 average scores). Strict commenting rules can prove high uncertainty avoidance on the Facebook pages when critical comments are ignored or deleted. Companies also avoid posting third-party or provocative content.

Content analysis in 2020 reveals a lower level of collectivism than two years earlier, with an average score of 43. Consumer appeals have become more personal. Companies move from using the word 'we' to 'you.' There are still appeals to be a member of the community. Videos and photos often show the collective product consumption by a group of friends or family. They emphasize the power of family values and gender stereotypes. Parents and two children still represent a family, usually a son and a daughter (see on Figure 3). 


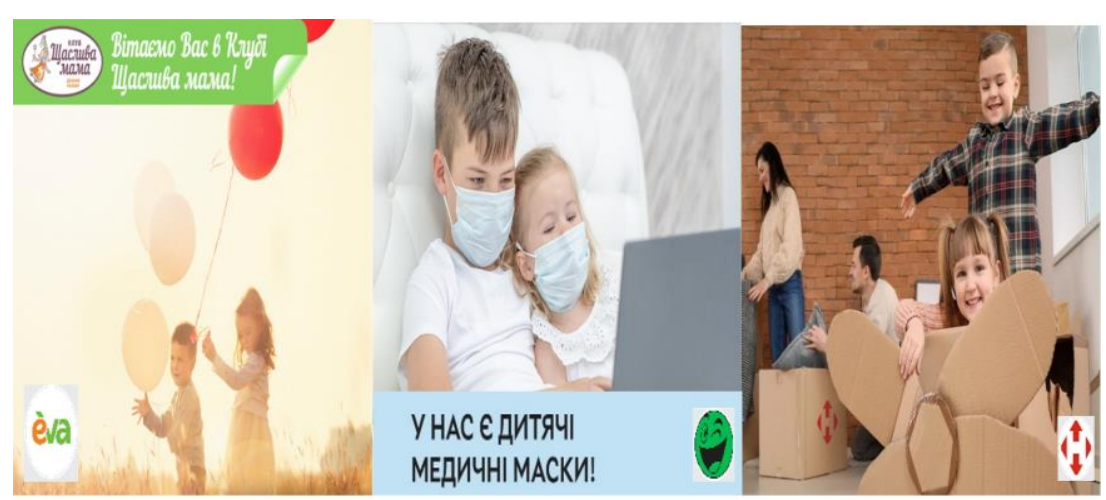

Figure 3. Gender \& social stereotypes on EVA, Rozetka \& Nova Noshta webpages (source: facebook.com/EVA.dp.ua/; facebook.com/rozetka.ua/; facebook.com/nova.poshta.official/)

Italian society is more collectivistic than Hofstede thought (average score is 60). In 2018, companies widely used the word 'we' in social media communications. In 2020, they switched to 'you' informal appeal to their readers (in Italian, like in Ukrainian, there are two forms of personal appeal--formal and informal). Pages invite visitors to join the community and post on the companies' Facebook pages. Posts focus more on the benefits of products for potential customers rather than the organization itself. Media figure employees in multi-gender groups and consumers or experts together involved in activities sponsored by the company (see Figure 4). In general, it should be noted much less activity on Italian pages compared to Ukrainian. New messages usually appear once every few days with a weekend break. This is a clear indication of the higher individuality of Italian society that appreciates its free time and is not ready to abandon it for business purposes.

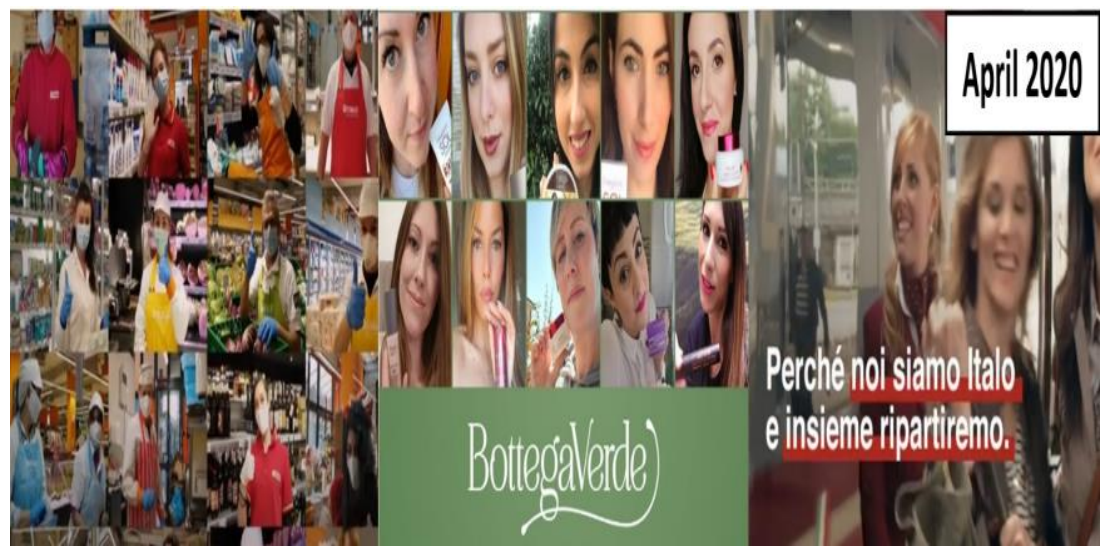

Figure 4. Collectivism on Conad, Bottega Verde \& Italo Treno webpages (source: facebook.com/Conad/; facebook.com/BottegaVerde/; facebook.com/ItaloTreno/)

Analyzed Ukrainian companies have a typical 'feminine' corporate culture (with a 23 average score) corresponding to Hofstede's findings. Companies avoid direct comparisons with competitors. In multi-gender or female audiences, advertising is dominated by content that displays positive non-verbal cues. Facebook moderators respond politely to even negative comments without deleting them. Such behavior is indicative of Ukrainian society trying to avoid conflicts. However, Ukrainians are also passionate, as they are patient, but to a certain extent. Revolutions of 2004 and 2014 evidenced that. In April 2020, media content again began to show the archetypes of hero, 
savior, strong man and woman. People are tired of quarantine and are waiting for a miracle.

The communication activity of Italian companies instead shows an inclination towards masculinity (average score is 53). Companies focus more on their products, not consumers. Sales promotions require some material gain. The archetypes of a hero and a strong man are often used. With the Covid-19 pandemic, Ukrainian companies have begun to focus more on social responsibility (see Figure 5). By April 2020, each company shared at least five news about charity actions made. Such behavior is typical for the entire Ukrainian business and is evidence of its reorientation to longer-term goals. Companies are trying to build CRM systems and are focusing on long-term benefits of products' and services' consumption. However, advertising still demonstrates ready-made behavioral patterns following the dominant social stereotypes. So, the long-term orientation index remains average $(50)$.

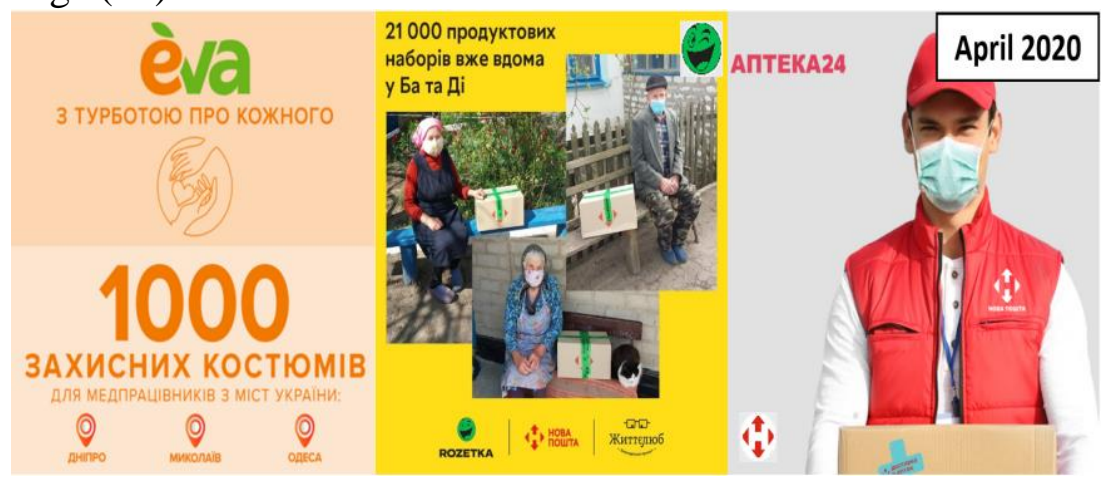

Figure 5. EVA, Rozetka \& Nova Noshta social responsibility actions (source: facebook.com/EVA.dp.ua/; facebook.com/rozetka.ua/; facebook.com/nova.poshta.official/)

Significant discrepancies in Hofstede's estimates are observed regarding long/shortterm orientation in Italy drifting towards a short-term pole (33). It is manifested in the limited participation of companies in charity events, their focus on maintaining traditions by demonstrating ready-made patterns of consumer behavior.

The indulgence level in Ukraine displays significant differences from Hofstede's estimates (37 average scores). Corporate website visitors are encouraged to participate in competitions in a dynamic and expressive language and enjoy being part of the community. Facebook pages do not contain warnings about inappropriate content banning and posting rules. There is a great variety of media bounded to local popular culture. Media messages are colorful, filtered, and executed in corporate colors. This reproduces the general situation in Ukraine, established after the 2014 Revolution of dignity, that destroyed the Soviet tradition of being modest and inconspicuous. In recent years, Ukrainians have shown a more relaxed attitude towards a person's desire to enjoy life.

Significant discrepancies in Hofstede's estimates are also observed in Italy that feels comfortable with a public demonstration of happiness (57 average Indulgence score). We think it may be connected to the economic problems and the general fatigue of Italian society during the coronavirus lockdown. After overcoming the pandemic, we should expect an even more significant demonstration of freedom and rejection of any restrictions. Companies' Facebook pages contain entertaining content made in bright colors and informal appeals to subscribers. 


\section{Discussion}

In general, it is possible to document the constant dynamics of a country's cultural environment. Certain culture-generating factors can remain relatively stable for decades (for example, the level of individualism or masculinity). Other factors are dynamic, requiring their constant monitoring. Repeated studies allow recalibrating the obsolete Hofstede's indexes for cultural dimensions and enable comparisons at multiple levels, within and across countries. Lo et al. (2017) suggested repeating cultural studies as a robustness check and narrowing it down to samples equivalent in size to obtain more solid results. Moreover, they argued that carrying this inquiry to ascertain differences across industries could lead to exciting results.

Two main assumptions guided our research. The first assumption inferred that traditional cultural values developed by (G. Hofstede, 1980; G. Hofstede, 2001) and House et al. (2004) are still topical and pertinent to social media as a new form of communication. The second assumption presupposed what scholars are theorizing as to the possible emergence of a new virtual culture introduced by technology that is bypassing traditional political boundaries and cultures while being, at the same time, grounded in them (Croucher, 2011; McEwan \& Sobre-Denton, 2011).

We observed mixed outcomes from our inquiry, aiming at investigating the impact of Hofstede's cultural framework on Ukrainian and Italian firms' usage of social media, notably Facebook. Even if the mean scores for the six companies are akin when looking at the inclusive sum of the two indices, analytical cross-cultural variances emerged. This suggests that cultural alteration appears on Facebook. The inquiry's research questions empower us to discover where the cultural indicators are most mirrored. However, when the study is commented as a whole, it witnesses that features conventionally characterizing cultures might not be so effective and robust on Facebook for corporations. In our research, traditional cultural frameworks proved not fully elucidatory and explained online behavior when applied to virtual business communication on social media. This may be due to inaccuracies or miscalculations or that companies are struggling to build and extend their social media presence globally and, in the process, depart from well-established cultural patterns of a specific country or region.

Nevertheless, even if Facebook exhibits the most significant number of users and the highest penetration rate, it is still one of the many popular social media platforms. Retabling this experiment on other social platforms and with different cultures may yield thought-provoking findings. Moreover, concentrating on factors hitherto overlooked, which may affect how social media are employed, could alter the results.

We concede that our own cultural bias might have prejudiced our perspective. We strongly recommend involving researchers of different origins who could work independently in a multicultural research team and cross-reference the results. In addition, all Facebook profiles under scrutiny were communicating and interacting, for the most part, in languages different from English. Albeit profiles were coded and translated accurately, it is likely that slang and bounded cultural phrases, particularly notable in Internet and social media communication, may have been misinterpreted.

Furthermore, social media communication is threatening the way customer services are offered and how marketing and promotional strategies are implemented. For this reason, more inclusive studies and further research is needed to investigate this emerging phenomenon of global virtual culture and what determines users' preferences and online attitudes. As stated in the introduction, the foremost critics of Hofstede's framework 
revolve around outdated and unreliable data. Moreover, Hofstede's dichotomized way of portraying cultural differences results in inexcusable generalizations. It ignores the subtle alterations and common ambiguities. Other criticisms express the need for exploring new insightful measures of distance (Beugelsdijk et al., 2017) and the need for discerning culture and country effects in carrying out tests. The outcomes of our study support these criticisms.

To thrive in this new landscape, corporations and firms should elaborate and produce marketing plans and campaigns on social media based on the predominant cultural characteristics in their segment and target market more than just a specific country or region. Even if marketing strategies are generally nation-based, the emergence of a new global virtual culture leads to the emergence of novel global segments and targets that will need to be addressed with a marketing strategy that favors standardization over adaptation. Another valuable alternative might be a 'glocal' (global and local) combined approach, where companies leverage the ubiquity provided by the Web while still valuing the peculiarities of the cultures they are addressing (Ess \& Sudweeks, 2006)

When relations among individuals in the firms entail social media platforms, some guidelines and terms of use should be outlined regarding attributes of specific cultural dimensions observable in employees and stakeholders to favor a productive working environment. In this way, social media characteristics can be adapted and adjusted to particular cultural dimensions reflective of users' cultural attitudes and preferences, irrespective of their country of origin or source culture. Hence, it becomes essential for marketers and scholars to gather data helpful in forecasting the consumers' online behavior. It should be based on demographic characteristics like social media usage patterns, hobbies, and social background, including multi-level approaches that promote cross-comparisons of results within countries.

Since the second phase of our study was conducted during the first phase of the Covid-19 quarantine, this allowed us to see trends in the cultural environment of the analyzed countries more clearly. However, this may also be a limitation of this study. For example, a high level of collectivism in Italy may result from lockdown, demonstrating the importance of family and commune in overcoming isolation obstacles. Economic problems in Italy have changed its priorities. The business aims to survive, and therefore to achieve short-term goals. Further research on the proposed methodology should verify if these trends prevail in the future. Using the same methodology for other nations and cultures may clarify Covid-19 consequences in different cultures--a hot topic for recent academic studies (Gokmen et al., 2021; Huynh, 2020; Pantano et al., 2021; Rajkumar, 2021; Shapoval et al., 2021; Shiwei \& Zhang, 2021; Wang, 2021; Webster et al., 2021),

\section{Conclusion}

Summarizing, we can conclude that there are no significant industry differences in the cultural manifestations of the analyzed companies' social activity in Ukraine and Italy. Ukrainian business is still aimed at collaborative problem solving, compliance with social standards, and the value of human life. It demonstrates a low level of power distance and avoiding uncertainty. Ukrainians express a critical attitude towards the authorities and their willingness to take risks, protecting society and their values. They understand the need for changes and are ready to welcome a person's desire to receive joy and pleasure from life. We can say that Ukraine is gradually changing its paradigm of thinking to a more hedonic and individualistic like Western Europe. In contrast, Italy shows less 
respect for power in all its manifestations and a greater willingness to take risks. The country has become less goal-oriented and restrained. Italians are ready to enjoy "dolce vita" publicly. However, they continue to complain about life, even though it is simpler in Italy than in Ukraine. Italy shows a higher level of collectivism and femininity than before. It also became highly short-term oriented. Meanwhile, the authors have created a list of 10 questions for each of the 6 Hofstede dimensions, that hope other scientists to apply it in their countries and industries.

\section{Conflict of Interest}

We certify that there is no conflict of interest with any financial, personal, or other relationships with other people or organizations related to the material discussed in the manuscript.

\section{Acknowledgments}

The authors would like to thank colleagues from the Taras Shevchenko National University of Kyiv and Libera Università Internazionale Degli Studi Sociali Guido Carli for the inspiring atmosphere of collaboration and scientific growth.

\section{References}

Beugelsdijk, S., Kostova, T., \& Roth, K. (2017). An overview of Hofstede-inspired country-level culture research in international business since 2006. Journal of International Business Studies, 48(1), 30-47. https://doi.org/10.1057/s41267-0160038-8

Blyznyuk, T., \& Lepeyko, T. (2016). Profile of modern Ukrainian manager. Proceedings Cross-Cultural Business Conference 2016, School of Management, Steyr Campus, 256-266.

Bottega Verde. (n.d.). Home [Facebook page]. Facebook. Retrieved May 8, 2020, from https://www.facebook.com/BottegaVerde/

Cheng, W., Hung, L., \& Chien, C. (2011). Cultural diversity and information and communication impacts in language learning. International Education Studies, 4(2), 111-115. https://doi.org/10.5539/ies.v4n2p111

Čiburienè, J., Guščfinskienè, J., \& Orehova, T. (2007). The Changes of Cultural Values: Lithuanian and Ukrainian Case. Socialiniai tyrimai [Social Research], 2(10), 3338.

Clark, T. (2003). Book Reviews. Journal of Marketing, 67(2), 151-153, https://doi.org/10.1509/jmkg.67.2.151.18611

Conad. (n.d.). Home [Facebook page]. Facebook. Retrieved May 8, 2020, from https://www.facebook.com/Conad/

Croucher, S.M. (2011). Social networking and cultural adaptation: A theoretical model. Journal of International and Intercultural Communication, 4(4), 259-264. https://doi.org/10.1080/17513057.2011.598046

Dadgar, M., Vithayathil, J., \& Osiri, J.K. (2017). Social Media Usage and Cultural Dimensions: An Empirical Investigation. Proceedings of the 50th Hawaii International Conference on System Sciences. http://hdl.handle.net/10125/41426

De Long, D.W., \& Fahey, L. (2000). Diagnosing cultural barriers to knowledge management. Academy of Management Executive, 14(4), 113-127. https://doi.org/10.5465/ame.2000.3979820 
Ess, C., \& Sudweeks, F. (2006). Culture and computer-mediated communication: Toward new understandings. Journal of Computer-Mediated Communication, 11(1), 179191. https://doi.org/10.1111/j.1083-6101.2006.tb00309.x

Eva. (n.d.). Home [Facebook page]. Facebook. Retrieved May 8, 2020, from https://www.facebook.com/EVA.dp.ua/

Ford, D.P., \& Chan, Y.E. (2003). Knowledge sharing in a multicultural setting: a case study, Knowledge Management Research and Practice, 1(1), 11-27. https://doi.org/10.1057/palgrave.kmrp.8499999

Fu, W.W., \& Govindaraju, A. (2010). Explaining global box-office tastes in Hollywood films: Homogenization of national audiences' movie selections. Communication Research, 37(2), 215-238. https://doi.org/10.1177\%2F0093650209356396

Garcia-Gavilanes, R., Quercia, D., \& Jaimes, A. (2013). Cultural dimensions in Twitter: Time, individualism and power. Proceedings of the 7th International AAAI Conference on Weblogs and Social Media (ICWSM). https://www.aaai.org/ocs/index.php/ICWSM/ICWSM13/paper/view/6102/6358

Gokmen, Y., Baskici, C., \& Ercil, Y. (2021). The impact of national culture on the increase of Covid-19: A cross-country analysis of European countries. International Journal of Intercultural Relations, 81, 1-8. https://doi.org/10.1016/j.ijintrel.2020.12.006

Gravili, G. (2016). Sharing Knowledge through Social Media: The Influence of National Cultures. Proceedings of the 2016 International Conference on Artificial Intelligence: Technologies and Applications (ICAITA 2016). https://doi.org/10.2991/icaita-16.2016.34

Hajro, A., Gibson, C.B., \& Pudelko, M. (2017). Knowledge exchange processes in multicultural teams: Linking organizational diversity climates to teams' effectiveness. Academy of Management Journal, 60(1), 345-372. https://doi.org/10.5465/amj.2014.0442

Hofstede Insights (n.d.). Geert Hofstede Country Comparison Tool. Retrieved May 8, 2020, from https://www.hofstede-insights.com/country-comparison/italy,ukraine/

Hofstede, G. \& Bond, M.H. (1988). The Confucius connection: from cultural roots to economic growth. Organizational Dynamics, 16(4), 4-21. https://doi.org/10.1016/0090-2616(88)90009-5

Hofstede, G. (1980). Culture's consequences: international differences in work-related values. Sage Publications.

Hofstede, G. (1991). Cultures and organizations: software of the mind. McGraw-Hill.

Hofstede, G. (2001). Culture's consequences: comparing values, behaviors, institutions and organizations across nations (2nd ed.). Sage Publications.

Hofstede, G., Hofstede, G.J. \& Minkov, M. (2010). Cultures and organizations: software of the mind (3rd ed.). McGraw-Hill.

House, R.J., Hanges, P.J., Javidan, M., Dorfman P.W. \& Gupta V. (2004). Culture, Leadership, and Organizations. The GLOBE Study of 62 Societies. Sage Publishing. 
Huanga, S., \& Crotts, J. (2019). Relationships between Hofstede's cultural dimensions and tourist satisfaction: A cross-country cross-sample examination. Tourism Management, 72, 232-241. https://doi.org/10.1016/j.tourman.2018.12.001

Huynh, T.L.D. (2020). Does culture matter social distancing under the COVID-19 pandemic? Safety Science, 130, 104872. https://doi.org/10.1016/j.ssci.2020.104872

Italo Treno. (n.d.). Home [Facebook page]. Facebook. Retrieved May 8, 2020, from https://www.facebook.com/ItaloTreno/

Johnston, K., \& Johal, P. (1999). The Internet as a virtual cultural region: Are extant cultural classification schemes appropriate? Internet Research, 9(3), 178-186.

Kirkman, B.L., Lowe, K.B., \& Gibson, C.B. (2006). A quarter century of Culture's Consequences: A review of empirical research incorporating Hofstede's cultural value framework. Journal of International Business Studies, 37(3), 285-320. https://doi.org/10.1057/palgrave.jibs.8400202

Kochkina, N. (2019). "Dynamics of PESTLE Factors of Ukrainian Market Environment", in Bele, D., Weis, L., Maher, N. (Eds.), Sustainable Development under Conditions of European Integration, Part 1, Ljubljana School of Business, pp. 250-265. https://www.researchgate.net/publication/333602437_DYNAMICS_OF_PESTLE _FACTORS_OF_UKRAINIAN_MARKET_ENVIRONMENT

Krishen, A.S., Berezan, O., Agarwal, Sh., Kachroo, P., \& Raschke, R. (2021). The digital self and virtual satisfaction: A cross-cultural perspective. Journal of Business Research, 124, 254-263. https://doi.org/10.1016/j.jbusres.2020.11.056

Laitinen, E.K., \& Suvas, A. (2016). Financial distress prediction in an international context: Moderating effects of Hofstede's original cultural dimensions. Journal of Behavioral and Experimental Finance, 9, 98-118. https://doi.org/10.1016/j.jbef.2015.11.003

Lee-Won, R.J., Shim, M., Joo, Y.K., \& Park, S.G. (2014). Who put the best "face" forward on Facebook?: Positive self-presentation in online social networking and the role of self-consciousness, actual-to-total Friends ration, and culture. Computers in Human Behavior, 39, 413-423. https://doi.org/10.1016/j.chb.2014.08.007

Levine, R. (2006). A Geography of Time: The Temporal Misadventures of a Social Psychologist or How Every Culture Keeps Time Just a Little Bit Differently. University Press.

Lo, K.D., Waters, R.D., \& Christensen, N. (2017). Assessing the applicability of Hofstede's cultural dimensions for Global 500 corporations' Facebook profiles and content. Journal of Communication Management, 21(1), 51-67. https://doi.org/10.1108/JCOM-04-2016-0021

Marcus, A., \& Gould, E.W. (2000). Crosscurrents: Cultural Dimensions and Global Web User Interface Design. Interactions, 7(4), 32-46. https://doi.org/10.1145/345190.345238

Mazanec, J.A., Crotts, J.C., Gursoy, D., \& Lu, L. (2015). Homogeneity versus heterogeneity of cultural values: An item-response theoretical approach applying Hofstede's cultural dimensions in a single nation. Tourism Management, 48, 299304. https://doi.org/10.1016/j.tourman.2014.11.011

McEwan, B. \& Sobre-Denton, M. (2011). Virtual cosmopolitanism: Constructing third cultures and transmitting social and cultural capital through social media. Journal of International and Intercultural Communication, 4(4), 252-258. https://doi.org/10.1080/17513057.2011.598044 
Minkov, M. (2007). What makes us different and similar: A new interpretation of the World Values Survey and other cross-cultural data. Klasika i Stil.

Minkov, M., Kaasa, A. (2021). A Test of the Revised Minkov-Hofstede Model of Culture: Mirror Images of Subjective and Objective Culture across Nations and the 50 US States. Cross-Cultural Research, 55(2-3), 230-281. https://doi.org/10.1177/10693971211014468

Na, J., Kosinski, M., \& Stillwell, D.J. (2015). When a new tool is introduced in different cultural contexts: Individualism-collectivism and social network on Facebook. Journal of Cross Cultural Psychology, 46(3), 355-370. https://doi.org/10.1177/ 0022022114563932

Nova Poshta. (n.d.). Home [Facebook page]. Facebook. Retrieved May 8, 2020, from https://www.facebook.com/nova.poshta.official/

Orlikowski, W.J., \& Barley, S.R. (2001). Technology and Institutions: What Can Research on Information Technology and Research on Organizations Learn From Each Other? MIS Quarterly 25(2), 145-165. https://doi.org/10.2307/3250927

Pantano, E., Priporas, C., Devereux, L., \& Pizzi, Gabriele (2021). Tweets to escape: Intercultural differences in consumer expectations and risk behavior during the COVID-19 lockdown in three European countries. Journal of Business Research, 130, 59-69. https://doi.org/10.1016/j.jbusres.2021.03.015

Picoto, W.Ng, \& Pinto, I. (2021). Cultural impact on mobile banking use - A multimethod approach. Journal of Business Research, 124, 620-628. https://doi.org/10.1016/j.jbusres.2020.10.024

Porter, M.E. (2001). Strategy and the Internet. Harvard Business Review, March 2001. https://www.gospi.fr/IMG/pdf/strategy-and-the-internet-porter-hbr-2001.pdf.

Prakash, C.D., \& Majumdar, A. (2021). Analyzing the role of national culture on content creation and user engagement on Twitter: The case of Indian Premier League cricket franchises. International Journal of Information Management, 57, April 2021, 102268. https://doi.org/10.1016/j.ijinfomgt.2020.102268

Rajkumar, R.Ph. (2021). The relationship between measures of individualism and collectivism and the impact of Covid-19 across nations. Public Health in Practice, 2, 100143. https://doi.org/10.1016/j.puhip.2021.100143

Richardson, R.M., \& Smith, S.W. (2007). The influence of high/low context culture and power distance on choice of communication media: Students' media choice to communicate with professors in Japan and America. International Journal of Intercultural Relations, 31(4), 479-501. https://doi.org/10.1016/j.ijintrel.2007.01.002

Rosen, L.D., Lim, A., Carrier, M., \& Cheever, N.A. (2010). An Empirical Examination of the Educational Impact of Text Message-Induced Task Switching in the Classroom: Educational Implications and Strategies to Enhance Learning, in Psicología Educativa, 17(2), 163-17. https://doi.org/10.5093/ed2011v17n2a4

Rozetka. (n.d.). Home [Facebook page]. Facebook. Retrieved May 8, 2020, from https://www.facebook.com/rozetka.ua/

Shapoval, V., Hagglund, P., Pizam, A., Abraham, V., Carlback, M., Nygren, T., \& Smith, R.M. (2021). The Covid-19 pandemic effects on the hospitality industry using social systems theory: A multi-country comparison. International Journal of Hospitality Management, 94, 102813. https://doi.org/10.1016/j.ijhm.2020.102813 Shestakovsky, O. (2014) Where are the cultural differences between the regions? 
Experience of the application of the methodology of G. Hofstede in Ukraine. Proceedings of conference: The Great Wars, the Great Transformations: Historical Sociology of the 20th Century. Kyiv, November 27-28, 2014, 1914- 2014.

Shiwei, H., \& Zhang, Yu. (2021). Covid-19 pandemic and firm performance: Crosscountry evidence. International Review of Economics \& Finance, 74, 365-372. https://doi.org/10.1016/j.iref.2021.03.016

Shuter, R. (2011). Introduction: New media across cultures-prospect and promise. Journal of International and Intercultural Communication, 4(4), 241-245. https://doi.org/10.1080/17513057.2011.598041

Socialbakers (2018a, August). August 2018 Social Marketing Report Ukraine. https://www.socialbakers.com/resources/reports/ukraine/2018/august

Socialbakers (2018b, August). August 2018 Social Marketing Report Italy. https://www.socialbakers.com/resources/reports/italy/2018/august/

Socialbakers (2020a, April). April 2020 Social Marketing Report Ukraine. https://www.socialbakers.com/resources/reports/ukraine/2020/april

Socialbakers (2020b, April). April 2020 Social Marketing Report Italy. https://www.socialbakers.com/resources/reports/italy/2020/april

Taras, V., Steel, P., \& Kirkman, B.L. (2012). Improving national cultural indices using a longitudinal meta-analysis of Hofstede's dimensions. Journal of World Business, 47(3), 329-341. https://doi.org/10.1016/j.jwb.2011.05.001

Taras, V., Steel, P., \& Kirkman, B.L. (2016). Does country equal culture? Beyond geography in the search for cultural boundaries. Management International Review, 56(4): 455-487. http://dx.doi.org/10.1007/s11575-016-0283-x

Urban, G. (2005). Don't just relate-Advocate! A blueprint for profit in the era of customer power. Wharton School Publishing.

Wackowski, K. \& Blyznyuk, T. (2017). Modern Ukrainian and Polish business cultures: G. Hofstede's classification. Economic Annals-XXI, 165(5-6), 71-74. https://doi.org/10.21003/ea.V165-15

Wang, Y. (2021). Government policies, national culture and social distancing during the first wave of the Covid-19 pandemic: International evidence. Safety Science, 135, 105138. https://doi.org/10.1016/j.ssci.2020.105138

Webster, G.D., Howell, J.L., Losee, J.E., Mahar, E.A., \& Wongsomboon, V. (2021). Culture, Covid-19, and collectivism: A paradox of American exceptionalism? Personality and Individual Differences, 178, 110853. https://doi.org/10.1016/j.paid.2021.110853

Wilson, M. (2010). An exploration of network and community theory and technosocial forms. Information, Communication \& Society, 13(5), 747-764. https://doi.org/10.1080/13691180903271572 